\title{
COMISSÃO DE CULTURA E EXTENSÃO UNIVERSITÁRIA DA ESCOLA DE ENFERMAGEM DE RIBEIRÃO PRETO DA UNIVERSIDADE DE SÃO PAULO
}

Maria Lúcia do Carmo Cruz Robazzi*

A Comissão de Cultura e Extensão Universitária da Escola de Enfermagem de Ribeirão Preto da Universidade de São Paulo durante os anos de 1991 e 1992 gerenciou cursos e eventos, conforme dados constante das tabelas abaixo:

1991

\begin{tabular}{|l|c|c|c||}
\hline \multicolumn{1}{|c|}{ Natureza } & Quantidade & $\begin{array}{c}\text { Carga } \\
\text { Horária }\end{array}$ & $\begin{array}{c}\text { N. }{ }^{\circ} \text { de } \\
\text { Participantes }\end{array}$ \\
\hline Especialização & 02 & 1.560 & 16 \\
\hline Difusão cultural & 08 & 121 & 368 \\
\hline Aperfeiçoamento & 03 & 136 & 57 \\
\hline Atualização & 02 & 47 & 45 \\
\hline Extensão & 15 & 598 & 354 \\
\hline Encontros & 03 & - & - \\
\hline Outros & 15 & - & - \\
\hline
\end{tabular}

*Presidenta da Comissão de Cultura e Extensão Universitária e Professora Doutora do Departamento de Enfermagem Geral e Especializada da Escola de Enfermagem de Ribeirão Preto da Universidade de São Paulo. 


\begin{tabular}{|l|c|c|c|}
\hline \multicolumn{1}{|c|}{ Natureza } & Quantidade & $\begin{array}{c}\text { Carga } \\
\text { Horária }\end{array}$ & $\begin{array}{c}\text { N. }{ }^{\circ} \text { de } \\
\text { Participantes }\end{array}$ \\
\hline Especialização & - & - & - \\
\hline Difusão cultural & 14 & 250 & 278 \\
\hline Aperfeiçoamento & 01 & 180 & 05 \\
\hline Atualização & 15 & 458 & 419 \\
\hline Extensão & 02 & 120 & 39 \\
\hline Encontros & 03 & 34 & 240 \\
\hline Outros & 15 & 159 & 4.100 \\
\hline TOTAL & $\mathbf{4 2}$ & $\mathbf{1 . 2 0 1}$ & $\mathbf{5 . 0 8 1}$ \\
\hline
\end{tabular}

Durante o $1^{\circ}$ semestre de 1993 , os Departamentos da Unidade ofereceram os seguintes cursos:

\begin{tabular}{|l|c|c|}
\hline \multicolumn{1}{|c|}{ Natureza } & Quantidade & $\begin{array}{c}\text { Carga } \\
\text { Horária }\end{array}$ \\
\hline Difusão cultural & 12 & 240 \\
\hline Atualização & 10 & 436 \\
\hline Universidade Aberta à 3a idade** & 1 & - \\
\hline
\end{tabular}

\section{$2^{\circ}$ Semestre de 1993}

Serão oferecidos os seguintes Cursos:

\section{Difusão Cultural}

01. "Diabetes Mellitus: considerações sobre a doença e cuidados básicos"
N. ${ }^{\circ}$ de vagas: 30 alunos
Carga horária: 8 horas

Período de inscrição: de 01 a 10.09 .93

02. "Detecção precoce da hipertensão arterial: fatores de risco e medida indireta da pressão arterial"
N. ${ }^{\circ}$ de vagas: 30 alunos
Carga horária: 8 horas

Período de inscrição: de 04 a 18.10 .93

**Projeto da Pró-Reitoria de Cultura e Extensão Universitária, aberta a graduados com idade superior a 60 anos. 
03. "Princípios básicos da cicatrização e o atendimento ao paciente na realização de curativo"

N. ${ }^{\circ}$ de vagas: 30 alunos Carga horária: 8 horas

Período de inscrição: 30.08 a 03.09.93

\section{Atualização}

01. "Assistência integral ao trinômio: mãe-pai-filho no processo do aleitamento materno"

N. ${ }^{\circ}$ de vagas: 50 vagas Carga horária: 40 horas

Período de inscrição: 01.09 a 17.10 .93

Quadragésimo Aniversário da Escola de Enfermagem de Ribeirão Preto da Universidade de São Paulo

Este ano nossa Unidade completa quarenta anos. Iniciou suas atividades em 10 de agosto de 1953, preparando enfermeiros, docentes, pesquisadores e especialistas de elevada competência técnica-científica.

Como parte da programação de comemoração do seu quadragésimo aniversário, estará realizando no período de 10 a 13 de agosto o "Encontro Nacional de Enfermagem sobre Ensino, Pesquisa e Serviços Extensão a Comunidade".

\section{PROGRAMA}

\section{Dia 10.08.93}

\section{0 horas}

- Sessão Solene de Abertura das Festividades, com apresentação da Orquestra Sinfônica de Ribeirão Preto.

- Retrospectiva Histórica da EERP-USP

- Sessão de homenagens com lançamento de botton e selo comemorativo.

Local: Teatro Municipal de Ribeirão Preto

\section{Dia 11.08.93}

\section{9 horas}

- Conferência: "Diretrizes da Educação em Enfermagem e o novo currículo de Enfermagem"

- Prof ${ }^{-}$Dr $^{\underline{a}-}$ Maria Auxiliadora Córdova Christófaro (ABEn. Nacional).

- Conferência: "O Ensino de Graduação na EERP-USP e suas perspectivas" - Prof $^{-a}$ Dr $^{\text {a }}$ Dulce Maria Vendrúsculo de Freitas (EERP-USP).

\section{3 horas}

- Sessão Pôster de trabalhos científicos de alunos de graduação em Enfermagem. 


\section{4:30 hs}

- Mesa Redonda "Escola de Enfermagem: desempenho de novos papéis".

$17: 30$ hs

- Entrega do prêmio ao melhor trabalho científico de aluno de graduação.

Local: EERP /USP

\section{Dia 12.08.93}

\section{3 horas}

- Sessão de Pôster de pesquisa em Enfermagem (exceto dissertações e teses).

\section{4:30 hs}

- Mesa Redonda: "Pesquisa no Brasil".

\section{$17: 30$ hs}

- Entrega do prêmio ao melhor trabalho científico de aluno de pós-graduação.

Local: EERP /USP

\section{Dia 13.08.93}

\section{9 horas}

- Conferência: A importância da Cultura e Extensão na Universidade. Prof. Dr. João Alexandre Barbosa (Prof. Reitor de Cultura e Extensão Universitária da Universidade de São Paulo).

\section{2 horas}

- Revoada de Pombos

\section{3 horas}

- Almoço de adesão

Local: EERP /USP

Durante o evento haverá exposição de memorial fotográfico, objetos e vídeo relativos aos 40 Anos da EERP-USP.

Maiores informações sobre as atividades coordenadas pela Comissão de Cultura e Extensão Universitária da EERP-USP poderão ser obtidas através do telefone (016) 633.1190 - ramal 205. 